\title{
Desafios da Divulgação do Património Arte Nova em Portugal
}

\author{
Filipe Serra Carlos \\ FLUP/Doutoramento em Estudos do Património (DEP) \\ filipeserracarlos@gmail.com
}

\section{Resumo}

Uma vez substituída por novos modos de fazer arquitetura e paradigmas decorativos, a Arte Nova foi remetida para o limbo das modas passadas, sofrendo uma depreciação que ditou a perda de muitas obras de arte. Em linha com um movimento internacional que resgatou a Arte Nova, em Portugal a sua revalorização teve início com os primeiros estudos, efetuados nos anos 1950, e ganhou força com o início da classificação de imóveis desta estética, nos anos 1970. Desde então, percorreu-se um caminho que permitiu à Arte Nova sair dos meios académicos e institucionais, procurando dar a conhecer este património junto de um público mais alargado. Pretende-se, com este capítulo, esboçar um retrato da forma como se tem feito a divulgação e a comunicação da Arte Nova, um retrato cujos traços gerais passam pelas iniciativas desenvolvidas ao longo dos anos assim como pelas entidades determinantes. Trata-se de um percurso que interessa conhecer, porque contribui para se compreender como a Arte Nova em Portugal é valorizada hoje em dia pelas entidades responsáveis e pela sociedade em geral. Por outro lado, contribui para identificar alguns equívocos que perduram sobre a Arte Nova, realçando a importância da divulgação e, especialmente, do aprofundamento do seu conhecimento.

Palavras-chave: Arte Nova; Portugal; património; Réseau Art Nouveau Network; inventário

\section{Challenges of the Diffusion of Art Nouveau Heritage in Portugal}

\begin{abstract}
As soon as it was replaced by new architecture practice and decoration design taste, Art Nouveau fell into the limbo of past fashions, becoming so depreciated that many works of art were destroyed. Like the international movement that rescued Art Nouveau, in Portugal its reappreciation begun with the first Art History studies made since the 50 's and became stronger after the listing of Art Nouveau buildings started in the 70's. Since, Art Nouveau has come a long way that allowed it to escape the academic and official institutes instances and that gave this heritage the opportunity to become known by a wider public. In this chapter, we aim to portray how diffusion and promotion of Art Nouveau related heritage has been done. Listing the initiatives that have been implemented as well as which entities were decisive in those processes are among this portrayal's main aspects. The relevance of knowing this evolution lies on the contribution it brings to the comprehension of how Art Nouveau is appreciated in Portugal
\end{abstract}


Carlos, Filipe Serra (2020). Desafios da divulgação do património Arte Nova em Portugal In Alice Duarte (ed.), Seminários DEP/FLUP vol. 1. Porto: Universidade do Porto, Faculdade de Letras/DCTP, p. 168-191. https://doi.org/10.21747/9789898969682/seminariosv1a8

nowadays by both responsible entities and society. It also allows identifying some lingering misconceptions about Art Nouveau, thus underlining the importance of its promotion and, also, of improving the Art Nouveau knowledge.

Keywords: Art Nouveau; Portugal; heritage; Réseau Art Nouveau Network; listing

\section{Introdução}

A Arte Nova vive atualmente uma fase em que conhece uma ampla divulgação junto do grande público, resultado de um já longo caminho que a transformou de uma expressão artística esquecida num património que se luta por salvaguardar. Para melhor compreendermos como a Arte Nova em Portugal é atualmente entendida pelas entidades responsáveis e pela sociedade em geral, começaremos por enquadrar a forma como foi vista, no contexto alargado da sua paulatina valorização pelos meios académicos e institucionais. Partiremos, para tal, da revisão dos estudos que os meios académicos produziram, a partir dos anos 50 do século $X X$, e, seguidamente, da análise dos dados disponíveis online no Sistema de Informação para o Património Arquitetónico (SIPA) relativos à classificação de imóveis com os aspetos atribuíveis à Arte Nova.

De que forma a divulgação que hoje se faz da Arte Nova decorre daqueles fatores? Quais as ações e os agentes que têm sido determinantes? Orientados por estas questões, procuraremos, ao longo deste capítulo, fazer um retrato em traços gerais dos desafios da divulgação da Arte Nova em Portugal, para o que nos munimos de informação muito dispersa recolhida principalmente, ainda que não exclusivamente, online, recorrendo aos sites de instituições oficiais, assim como aos meios de comunicação social.

\section{O resgate da Arte Nova: conhecer a Arte Nova}

Em Portugal, é discreta a aparição do Art Nouveau, essa manifestação artística que será adaptada entre nós com a designação de Arte Nova. E tardia também, quando comparada com os principais centros europeus - como Paris ou Bruxelas, Viena ou Glasgow -, nos quais teve lugar muita da reflexão responsável pelos valores que enformam a nova estética. Para lá das características formais de que se reveste, em que coexistem as variadas interpretações nascidas naqueles locais, a Arte Nova é, antes de 
Carlos, Filipe Serra (2020). Desafios da divulgação do património Arte Nova em Portugal In Alice Duarte (ed.), Seminários DEP/FLUP vol. 1. Porto: Universidade do Porto, Faculdade de Letras/DCTP, p. 168-191. https://doi.org/10.21747/9789898969682/seminariosv1a8

mais, reflexo duma atitude dos artistas de finais do século XIX. Perante uma realidade social e económica marcada pela crescente industrialização que dita, não só a perda da qualidade estética dos produtos antes obtidos por métodos artesanais, como a própria decadência da qualidade de vida, cada vez mais arredada da ligação vivificante à Natureza de outrora, os artistas propõem uma renovada forma de fazer arte, na qual, a par com a aceitação dos processos industriais, se devolva o protagonismo ao belo. Este vai ser doravante procurado nas formas orgânicas da Natureza, tornadas emblemáticas da decoração Arte Nova, mas também no uso de novos materiais e técnicas, como o betão, no caso da arquitetura. Repudia-se, assim, também a realidade artística desse século, em que imperaram os formulários de revivalismo de todo o tipo de estilos artísticos passados ou exóticos.

Em suma, a Arte Nova foi um fenómeno resultante duma vontade deliberada de mudança, fazendo a transição para a arte moderna. A sua face mais reconhecível poderá ser o seu caráter de decoração aplicada a estruturas, mas o seu espírito, em particular no que respeita à arquitetura, encontrar-se-á não poucas vezes numa renovada conceção de volumetrias e espaços que superam aquela capa superficial. Expandindose por diversos países, os valores da

Arte Nova foram apropriados de formas variadas. Em Portugal, condicionaram o desenvolvimento da Arte Nova a industrialização incipiente, a falta de massa crítica nas academias e a crise económica e política que marcou a viragem do século (Fernandes, 1993). Por conseguinte, a Arte Nova manifesta-se, entre nós, de uma forma que é considerada geralmente mais intuitiva do que refletida, geralmente mais ao nível da decoração do que das estruturas e bastante breve, consequência da divulgação tardia e da rápida aceitação da Art Déco que se Ihe seguiu (França, 1966).

O ocaso da Arte Nova, entre nós, dá-se durante os anos 1920, não obstante se verifique na construção e, especialmente, na decoração de edifícios até aos anos 1930. Com o seu lugar disputado, a Arte Nova caiu no esquecimento destinado às modas passadas, com o que isso implicou em termos de vulnerabilidade à destruição de muitos dos exemplares que nos legou.

O interesse pela Arte Nova renasce nos anos 1950, época a partir da qual começou a ser objeto de estudos académicos, num processo em tudo similar ao que o Art Nouveau conhecia por este tempo na Europa. No primeiro artigo sobre o tema, 
Carlos, Filipe Serra (2020). Desafios da divulgação do património Arte Nova em Portugal In Alice Duarte (ed.), Seminários DEP/FLUP vol. 1. Porto: Universidade do Porto, Faculdade de Letras/DCTP, p. 168-191. https://doi.org/10.21747/9789898969682/seminariosv1a8

publicado em 1957, Manuel Rio-Carvalho traça o primeiro retrato da Arte Nova em Portugal, apresentando dela - especialmente por comparação com o Art Nouveau francês e belga - uma visão depreciativa que se viria a afirmar e que apenas lentamente tem vindo a mudar. Para este autor, a Arte Nova é um fenómeno "que não teve grande expressão entre nós. Em 1900, Portugal continuava, de uma maneira geral, agarrado aos estilos 'clássicos'” (Rio-Carvalho, 1957: p. 10). Para este autor, a Arte Nova em Portugal é mais decorativa do que arquitetónica, tal como já o era o Art Nouveau francês, que foi a sua maior influência. Sublinha que, enquanto fenómeno complexo que é, a Arte Nova portuguesa se reduz às formas e não corporiza as outras implicações que o Art Nouveau continha, pelo que "desligada do seu contexto simbolista, do Einfühlung, do ornato funcional, do desejo de industrialização, a 'Arte Nova' é uma nova pacotilha oitocentista, que não se distingue, a não ser a nível morfológico, do neogótico 'à la cathédrale' do ecletismo do Segundo Império" (Rio-Carvalho, 1974: p. 251). Tal justifica-o com as condições próprias da realidade portuguesa, como a fraca industrialização ou a fraca implantação do simbolismo.

Por outro lado, defende também que a Arte Nova em Portugal não se limitou a replicar as fórmulas francesas, pois incorporou algumas características autóctones, como o uso do azulejo. Não foi capaz, contudo, de se tornar uma manifestação completamente autónoma. Segundo ele, o nacionalismo, que era avesso às importações, e um certo folclorismo romântico, também condicionaram o florescimento da Arte Nova. A “Arte Nova é assim um testemunho de um processo especificamente nacional de rarefação dos movimentos importados, da desvirtualização das suas formas e da integração num contexto tradicional, pela reorganização de um novo esquema artístico" (Rio-Carvalho, 1966: p. 27).

Como explica Rio-Carvalho (1966), a Arte Nova acabou por ser muito limitada a um mercado composto principalmente de modestos proprietários e aplicada em pequenos prédios e obras de estabelecimentos comerciais, através da justaposição de azulejos, grades e esculturas decorativas. Alerta, também por isso, para a impossibilidade de se comparar a nossa produção artística pela bitola da francesa, pois com as circunstâncias distintas que aqui se viviam, naturalmente os resultados tinham de ser diferentes também. Propunha, neste artigo, "meditemos nas palavras de Manuel de Macedo: 'Cônscios, porém, da mediania dos nossos recursos, cessemos, por uma vez, 
Carlos, Filipe Serra (2020). Desafios da divulgação do património Arte Nova em Portugal In Alice Duarte (ed.), Seminários DEP/FLUP vol. 1. Porto: Universidade do Porto, Faculdade de Letras/DCTP, p. 168-191. https://doi.org/10.21747/9789898969682/seminariosv1a8

de ilustrar o apólogo da rã que tenta imitar o boi...' e apliquemo-las, a 70 anos de distância, à apreciação atual da Arte Nova" (Rio-Carvalho, 1966: p. 27), reconhecendo que era preciso parar de comparar a nossa com a francesa e apreciá-la tão-só pelo que é.

A Arte Nova foi mal compreendida pelos seus contemporâneos. Assim como não havia massa crítica que conferisse uma base teórica à Arte Nova em Portugal, essa massa crítica não estava preparada para compreender o fenómeno que chegava de fora. RioCarvalho, numa conferência em 1970, refere como exemplo as reações dos arquitetos Adães Bermudes ou Marques da Silva ou dos críticos Fialho e Ramalho. Por conseguinte, “Portugal teve a 'Arte Nova' que podia ter, uma 'Arte Nova' que foi um novo 'arrebique sobreposto', a juntar aos 'pastiches' neogóticos, neo-rococós, ecléticos, etc. [...] 0 assunto e a ocasião determinavam o 'estilo'” (Rio-Carvalho, 1974: p. 251).

Nuno Portas (1973) salienta que os arquitetos encartados, ao longo do século XIX e até à 1. - Guerra Mundial, mercê de vários fatores, como novas regulamentações e quantidade de construção à qual não conseguem dar resposta, veem o seu papel de autores de projetos disputado por outros profissionais: engenheiros, mestres de obras promovidos, decoradores, que, por serem menos exigentes culturalmente, se tornaram mais bem integrados nos mecanismos de promoção da nova estética. Por isso, alerta que no estudo da arquitetura do início do século $\mathrm{XX}$, ao considerar como relevantes apenas as obras dos arquitetos mais destacados, o historiador está a subestimar a importância e o significado sociocultural da arquitetura "anónima" (a que chama arquitetura de "série $B$ "). Assim, a visão negativa que vemos formar-se no início dos estudos sobre a Arte Nova, como fenómeno limitado e de reduzida expressão, deve-se, em certa medida, ao foco posto unicamente na obra de arquitetos renomados.

Nuno Portas (1973) também sublinha que aos arquitetos faltava o conhecimento do que se estava a fazer lá fora e que muita da Arte Nova que se fez resulta do que chegava por via da imprensa da época. Este facto contribui por sua vez para a relativa irrelevância com que se considera a Arte Nova, afirmando este autor:

não nos terá ficado talvez nenhuma arquitetura que se possa classificar de 'Arte Nova' ao nível de concepção inteira do edifício, para além de algumas lojas - padarias, um café, uma livraria, algumas retrosarias, um stand de automóveis, quiosques -, a bela decoração cerâmica exterior de um animatógrafo, os portões, gradeamentos, floreiras ou guarnecimentos de vãos em prédios de rendimento, que se considerarão sempre menores mas nem por 
Carlos, Filipe Serra (2020). Desafios da divulgação do património Arte Nova em Portugal In Alice Duarte (ed.), Seminários DEP/FLUP vol. 1. Porto: Universidade do Porto, Faculdade de Letras/DCTP, p. 168-191. https://doi.org/10.21747/9789898969682/seminariosv1a8

isso menos interessantes, que pontuam as zonas novas das 'baixas' comerciais da cidade, dando sinal de um gosto da pequena burguesia [...].(Portas, 1973: p. 703)

Numa entrevista em 1975, Rio-Carvalho considerava que era impossível conservar-se tudo, nem era necessário fazê-lo a todo o custo. "O que não acho necessário é conservar todos os prédios Arte Nova em Lisboa." (Rio-Carvalho, 1975: p. 300) e, por isso, deve-se tentar guardar um exemplar de Arte Nova de "cada espécie, portanto, um prédio de rendimento, uma moradia e uma loja" (Rio-Carvalho, 1975: p. 299). Como se vê, os primeiros estudos sobre a Arte Nova em Portugal não a valorizavam substancialmente, apesar de lhe trazerem visibilidade, e ainda nos anos 1970 era tratada como um fenómeno de somenos importância. Verificava-se, assim, um alinhamento entre os estudos académicos sobre este fenómeno e a destruição de exemplares que grassava ${ }^{1}$. Na mesma entrevista, percebe-se como já em 1975 o investimento necessário para restaurar certos imóveis Arte Nova representava uma grande dificuldade para a salvaguarda do património Arte Nova e Rio-Carvalho denuncia vários casos de más intervenções já realizadas. Realça, contudo, a existência de vários imóveis Arte Nova ainda em uso e em relativamente bom estado, chegando a propor a utilização de um deles para a instalação de um museu sobre a época da Arte Nova.

Inicialmente centrados na realidade lisboeta, os estudos realizados por esta época já reconhecem, como refere Rio-Carvalho, o Porto e Aveiro como polos de Arte Nova. No que respeita à região de Aveiro, explica que são "regiões onde não havia muito dinheiro, mas onde havia um dinheiro novo. Portanto, pessoas que tinham um dinheiro novo e, digamos, eram nitidamente progressistas e faziam coisas Arte Nova" (RioCarvalho, 1975: p. 300).

Já relativamente ao Porto, este autor refere que a Arte Nova tem o mesmo caráter que a de Lisboa ainda que em menor quantidade, ressalvando que, apesar das muitas perdas já verificadas, há ainda exemplos merecedores de serem conservados, como duas casas, "uma na Galeria de Paris e outra na Rua de Cândido dos Reis que são

\footnotetext{
${ }^{1}$ Esta noção tem-se vindo lentamente a inverter, à medida que se foram multiplicando, em particular desde os anos 1990, estudos que lançaram novos olhares e foram aprofundando o conhecimento sobre diferentes facetas da Arte Nova em Portugal, através de estudos focados em diferentes regiões portuguesas, estudos monográficos sobre um ou vários autores ou estudos com foco em manifestações específicas da Arte Nova (como a azulejaria, por exemplo).
} 
Carlos, Filipe Serra (2020). Desafios da divulgação do património Arte Nova em Portugal In Alice Duarte (ed.), Seminários DEP/FLUP vol. 1. Porto: Universidade do Porto, Faculdade de Letras/DCTP, p. 168-191. https://doi.org/10.21747/9789898969682/seminariosv1a8

peças de grande categoria, embora modestas" (Rio Carvalho, 1975: p. 300). Curiosamente, seriam do Porto as primeiras obras Arte Nova a serem classificadas em Portugal.

\section{O resgate da Arte Nova: quando a Arte Nova merece ser classificada}

O início da classificação de imóveis Arte Nova em Portugal reflete um interesse pelos exemplares desta estética que, como vimos, se pode atribuir ao destaque que the foi dado pelos estudos académicos até então realizados. A partir da consulta do Sistema de Informação para o Património Arquitetónico (SIPA)² é-nos possível fazer um esboço da evolução da inventariação e classificação de imóveis Arte Nova ou com aspetos Arte Nova. Os dados recolhidos através de uma pesquisa mostraram, desde logo, que foi nos anos 1970 que ocorreram as primeiras classificações de imóveis pelo seu caráter inequivocamente Arte Nova: trata-se de duas casas do Bairro das Carmelitas, no Porto, às quais Rio-Carvalho aludiu na entrevista de 1975 que atrás citámos, e que foram classificadas em 1974 (Figuras 1 e 2).
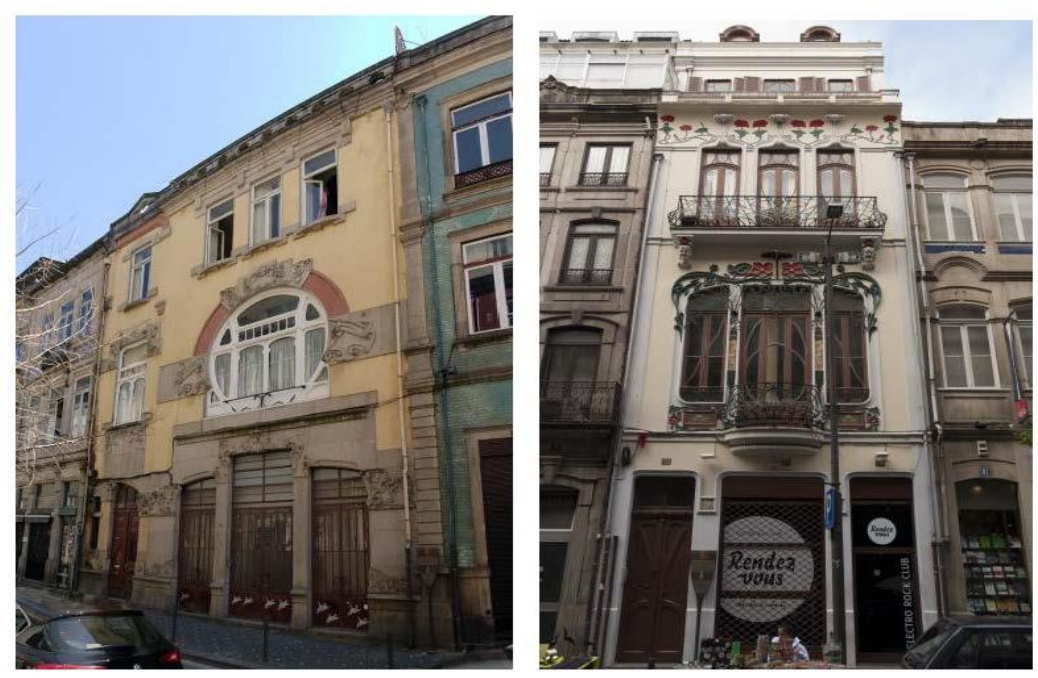

Figuras 1 e 2 - Casas Arte Nova do Bairro das Carmelitas, no Porto, classificadas em 1974: Rua da Galeria de Paris, n.o 28 (esq.) e Rua de Cândido dos Reis, n. ${ }^{\text {os }} 75$ a 79 (dir.).

\footnotetext{
${ }^{2}$ SIPA - Sistema de Informação para o Património Arquitetónico: http://www.monumentos.gov.pt
} 
Carlos, Filipe Serra (2020). Desafios da divulgação do património Arte Nova em Portugal In Alice Duarte (ed.), Seminários DEP/FLUP vol. 1. Porto: Universidade do Porto, Faculdade de Letras/DCTP, p. 168-191. https://doi.org/10.21747/9789898969682/seminariosv1a8

\subsection{A consulta global aos imóveis listados}

A consulta realizada através da pesquisa da expressão "arte nova" foi realizada entre setembro e outubro de 2019 e devolveu 215 ocorrências contendo aquela expressão nas fichas respetivas. Este número foi apurado após se terem excluído os resultados relativos a conjuntos urbanos contendo referências superficiais a Arte Nova. A esta lista somou-se ainda um imóvel do Porto que não aparece nos resultados da pesquisa, embora seja uma das duas casas referidas, classificadas em 1974 (a que se localiza na Rua de Cândido dos Reis, reconhecidamente um dos melhores exemplos de Arte Nova da Cidade Invicta). Ressalvamos, portanto, a existência de uma margem de erro que apenas passar em revista todas as entradas do SIPA permitiria obviar.

Uma parte das referências listadas corresponde a imóveis construídos de raiz nesta época, nos quais os aspetos Arte Nova são apenas detalhes decorativos, a mais das vezes ao nível dos frisos de azulejos ou das serralharias. Note-se também que, muitos dos casos listados - e classificados - são imóveis de épocas anteriores, mas com alguns aspetos Arte Nova resultantes de alterações ou acrescentos decorativos feitos ao longo do tempo.

A distribuição geográfica (Gráfico 1) destas situações, tomadas como um todo, revela que a maior concentração se encontra nos distritos de Lisboa (49 ocorrências), Aveiro (35) e Setúbal (29). Leiria, cidade que se distingue pela obra de Ernesto Korrodi, apresenta apenas 15 casos listados, assim como Faro. Contudo, da informação disponível nas fichas de inventário ressalta que os imóveis listados do distrito de Leiria são exemplos mais completos de Arte Nova, não se tratando apenas de imóveis com apontamentos decorativos em edifícios de construção relativamente convencional, como se verifica em muitos dos outros casos.

No que respeita especificamente aos imóveis classificados, constatou-se serem apenas 62 , pelo que constituem uma minoria no total de resultados devolvidos na busca realizada. Não considerámos neste cômputo os imóveis que se encontram abrangidos por zonas de proteção de outros sítios ou edifícios classificados (37 casos), pois, se é certo que essa circunstância representa uma forma de proteção por si só, tal não sucede graças ao valor atribuído especificamente a esses imóveis. Daqueles 62 imóveis considerados, temos assim que 50 estão classificados como imóveis de Interesse Público e 12 de Interesse Municipal. Não se verifica nenhuma classificação como Monumento 
Carlos, Filipe Serra (2020). Desafios da divulgação do património Arte Nova em Portugal In Alice Duarte (ed.), Seminários DEP/FLUP vol. 1. Porto: Universidade do Porto, Faculdade de Letras/DCTP, p. 168-191. https://doi.org/10.21747/9789898969682/seminariosv1a8

Nacional. Verificou-se ainda que 23 imóveis são indicados como estando em vias de classificação. Os demais 131 não estão classificados, havendo em sete casos referência expressa à existência, a dada altura, de processos de classificação que foram encerrados sem resultarem em nenhum tipo de classificação (Gráfico 2).

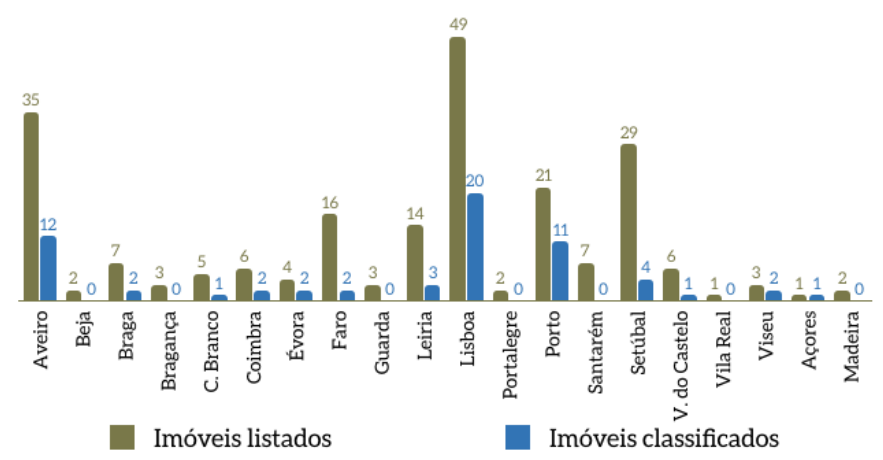

Gráfico 1 - Distribuição, por distritos, dos imóveis listados e classificados

Arte Nova ou com aspetos associáveis à Arte Nova.

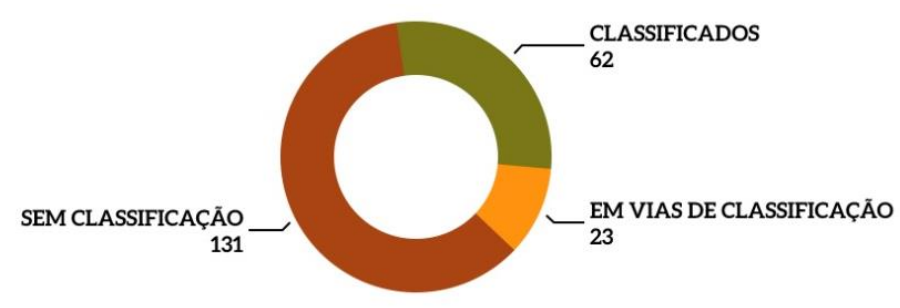

Gráfico 2 - Estatuto dos 216 imóveis listados.

Além dos 216 resultados considerados nesta análise, a consulta realizada devolveu ainda dez casos de imóveis em que a associação à Arte Nova estava mal atribuída. Prevalece uma confusão com a $\mathrm{Art} \mathrm{Déco}^{3}$, o movimento estético que sucedeu à Arte Nova, em sete casos. Mas surpreendeu principalmente a atribuição à Arte Nova de características de edifícios modernistas ${ }^{4}$, por exemplo, pelo simples facto de terem

\footnotetext{
${ }^{3}$ A título de exemplo, a Garagem Liz, em Lisboa (http://www.monumentos.gov.pt/Site/APP PagesUser/SIPA.aspx?id=3027), o Edifício da Pastelaria Dantas, em Viana do Castelo (http://www.monumentos.gov.pt/Site/APP PagesUser/SIPA.aspx?id=21903) ou o Quiosque do Serviço de Transportes Coletivos do Porto (http://www.monumentos.gov.pt/Site/APP PagesUser/SIPA.aspx?id=5545), consultados em 2019-0918.

${ }^{4}$ Por exemplo, o Cine-Teatro Joaquim de Almeida, no Montijo (http://www.monumentos.gov.pt/Site/APP PagesUser/SIPA.aspx?id=7029) e o Mercado Central Municipal do Montijo (http://www.monumentos.gov.pt/Site/APP PagesUser/SIPA.aspx?id=7026), consultados em 2019-09-18.
} 
Carlos, Filipe Serra (2020). Desafios da divulgação do património Arte Nova em Portugal In Alice Duarte (ed.), Seminários DEP/FLUP vol. 1. Porto: Universidade do Porto, Faculdade de Letras/DCTP, p. 168-191. https://doi.org/10.21747/9789898969682/seminariosv1a8

plantas livres e se caracterizarem pela assimetria das fachadas, em dois casos. Por estes exemplos, fica evidente algum desconhecimento da Arte Nova, mesmo entre uma comunidade - os técnicos que realizam o inventário do património - que, à partida, se espera que detenham conhecimentos sobre arquitetura superiores aos do público em geral.

\subsection{Os imóveis classificados}

Ao analisarmos mais atentamente o conjunto de imóveis que estão efetivamente classificados, verifica-se que, ao nível da distribuição geográfica, a maior concentração coincide com as regiões identificadas como sendo os polos mais relevantes da Arte Nova em Portugal, desde logo por Rio-Carvalho: Lisboa, com 19 casos, Aveiro, com doze e Porto, com onze.

Os imóveis classificados são maioritariamente edifícios da época, 43 imóveis construídos de raiz, nos quais em cerca de três dezenas o caráter Arte Nova se manifesta em mais do que apenas num ou noutro pormenor decorativo. Nota-se, por exemplo, ao nível da composição das fachadas e da articulação de volumes.

No extremo oposto da distribuição geográfica, sem nenhum imóvel com aspetos Arte Nova, classificados ou em vias de classificação, surgem os distritos de Beja, Guarda, Portalegre e a Madeira.

\subsection{Tipologias e ritmo das classificações:}

As tipologias de edifícios classificados são variadas, predominando os edifícios residenciais - casas, palacetes, prédios de habitação - e são, por norma, edifícios de encomenda privada. As referências a edifícios públicos são poucas, embora haja salas de espetáculo (teatros e cinemas) ou edifícios ligados a cuidados de saúde, como um sanatório ou um complexo termal, neste conjunto (Quadro 1). 
Carlos, Filipe Serra (2020). Desafios da divulgação do património Arte Nova em Portugal In Alice Duarte (ed.), Seminários DEP/FLUP vol. 1. Porto: Universidade do Porto, Faculdade de Letras/DCTP, p. 168-191. https://doi.org/10.21747/9789898969682/seminariosv1a8

\begin{tabular}{r|c}
\hline Edifícios residenciais & 42 \\
\hline Salas de espetáculo & 6 \\
\hline Sedes de associações & 3 \\
\hline Complexos de cuidados de saúde & 3 \\
\hline Hotéis & 2 \\
\hline Estabelecimentos comerciais & 2 \\
\hline Armazém & $\mathbf{1}$ \\
\hline Garagem & $\mathbf{1}$ \\
\hline Sede de Capitania & $\mathbf{1}$ \\
\hline Convento & $\mathbf{1}$ \\
\hline
\end{tabular}

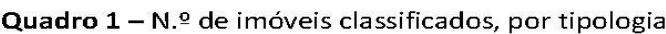

Os imóveis com aspetos Arte Nova classificados - e até os listados - não serão senão uma pequena parte do que existe de manifestações da Arte Nova em Portugal. No entanto, o ritmo a que se sucederam reflete uma crescente valorização de elementos artísticos Arte Nova, tanto por parte de quem classifica, como de quem promove as iniciativas de classificação, mesmo considerando que só o estudo dos processos de classificação de cada um destes imóveis permitiria perceber com exatidão o peso que os aspetos Arte Nova tiveram na obtenção da proteção.

Às primeiras classificações de sete imóveis, ocorridas nos anos 1970, seguiu-se um pico nos anos 1982-84, em que houve 14 classificações. Embora, depois disso, o ritmo tivesse abrandado, a última década voltou a ser marcada por um número de classificações bastante elevado - 21, entre 2011 e 2018 (Gráfico 3).

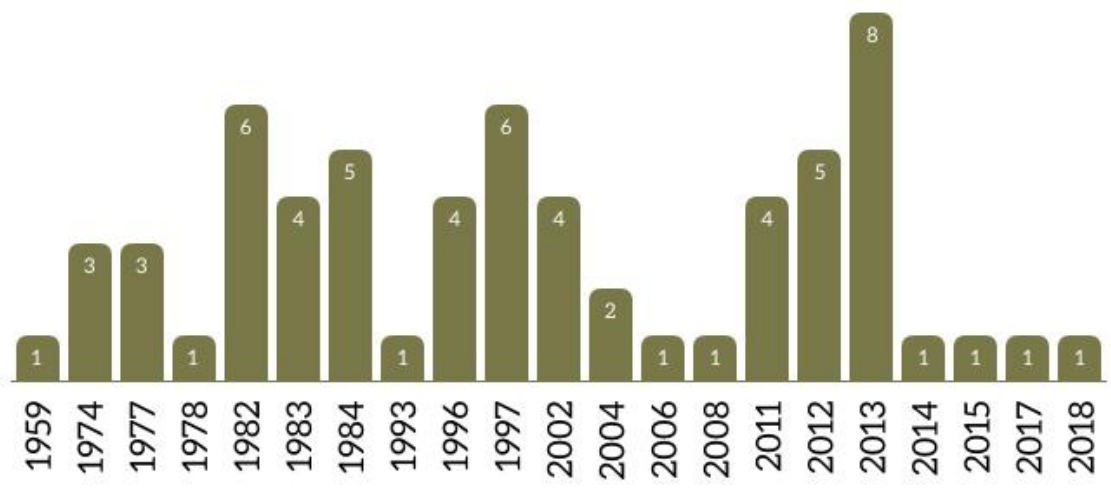

Gráfico 3 - Evolução das classificações de imóveis ${ }^{5}$.

\footnotetext{
${ }^{5}$ Para efeitos de contabilização dos imóveis com aspetos Arte Nova classificados, incluímos aqui o estudo do Convento do Salvador / Lar Conde de Agrolongo, classificado como Imóvel de Interesse Público desde 1959 (http://www.monumentos.gov.pt/Site/APP PagesUser/SIPA.aspx?id=46). No
} 
Carlos, Filipe Serra (2020). Desafios da divulgação do património Arte Nova em Portugal In Alice Duarte (ed.), Seminários DEP/FLUP vol. 1. Porto: Universidade do Porto, Faculdade de Letras/DCTP, p. 168-191. https://doi.org/10.21747/9789898969682/seminariosv1a8

Não obstante esta evolução, as perdas de Arte Nova continuam a acontecer todos os dias, mesmo em imóveis classificados. No distrito de Lisboa, foram desclassificados três imóveis por esses motivos: dois, em que os interiores dos prédios foram destruídos ${ }^{6}$, um, em que a loja Arte Nova do piso térreo de um prédio foi demolida.

Em sentido inverso, como referido, vários imóveis estão em estudo ou em vias de classificação, destacando-se nesse conjunto o distrito de Aveiro, com oito imóveis nessa situação. Seguem-se os distritos de Lisboa e Porto, cada um com quatro processos em curso. O lugar ocupado por Aveiro não é de estranhar, visto o esforço que esta região tem vindo a fazer no sentido de tornar a Arte Nova uma imagem de marca de identidade regional.

\subsection{Dar a conhecer a Arte Nova}

O esforço de divulgação junto de um público mais alargado decorre do reconhecimento da importância que o património tem para a construção da identidade de uma comunidade, mas também, e, cada vez mais, do reconhecimento do seu potencial estratégico em termos turísticos - e, portanto, económicos.

A nível nacional, esses vetores têm estado presentes em particular na estratégia da cidade de Aveiro, que desde o início do século XXI tem vindo a afirmar o seu estatuto de "capital da Arte Nova" como fator de diferenciação da região e como cartaz para captação de visitantes. Nos anos 1980 e 1990, a existência de brochuras e outros materiais impressos da responsabilidade da Câmara Municipal de Aveiro ou da Região de Turismo da Rota da Luz (Almeida, 2007: p. 63) evidenciava já o potencial da Arte Nova para a região, mas foi com o projeto de criação do Museu de Arte Nova e de parcerias com outras cidades que os testemunhos da Arte Nova ganharam uma outra importância e visibilidade.

\footnotetext{
entanto, como a sua classificação naquele ano não se deve ao seu caráter Arte Nova (elementos desta estética são diminutos), esta não invalida a afirmação de que as primeiras classificações de imóveis Arte Nova sejam as referidas de 1974.

${ }^{6}$ http://www.monumentos.gov.pt/Site/APP PagesUser/SIPA.aspx?id=3044, http://www.monumentos.gov.pt/Site/APP PagesUser/SIPA.aspx?id=2536 e http://www.monumentos.gov.pt/Site/APP PagesUser/SIPA.aspx?id=6486; consultados em 2019-09-19.
} 
Carlos, Filipe Serra (2020). Desafios da divulgação do património Arte Nova em Portugal In Alice Duarte (ed.), Seminários DEP/FLUP vol. 1. Porto: Universidade do Porto, Faculdade de Letras/DCTP, p. 168-191. https://doi.org/10.21747/9789898969682/seminariosv1a8

\subsection{Um Museu para a Arte Nova}

Numa comunicação de 2006, Gomes e Lourenço (2007) deixam claro que o projeto do Museu de Arte Nova estava já em marcha nesse ano. A sua implementação resultou de uma estratégia que previa impulsionar a inventariação do património Arte Nova, o estabelecimento de parcerias nacionais e internacionais entre Aveiro e outras localidades detentoras de relevante património Arte Nova e a sensibilização do público para este património. A inauguração do Museu aconteceu em 2012, tendo como objetivos principais, entre outros, aumentar o interesse pela Arte Nova, tornar a informação mais acessível, promover a investigação e associar-se à vida cultural da cidade (Gomes e Lourenço, 2007: p. 96). Para sua sede foi escolhido um dos edifícios mais emblemáticos da Arte Nova de Aveiro, a chamada Casa do Major Pessoa, construída entre 1907 e 1909 e da autoria Francisco da Silva Rocha, um dos nomes mais importantes da Arte Nova de Aveiro (Figura 3). Para acolher o Museu, a casa sofreu obras de restauro no sentido de valorizar o seu aspeto original ao mesmo tempo que era adaptada a um percurso expositivo (Providência e Providência, 2007: p. 104).

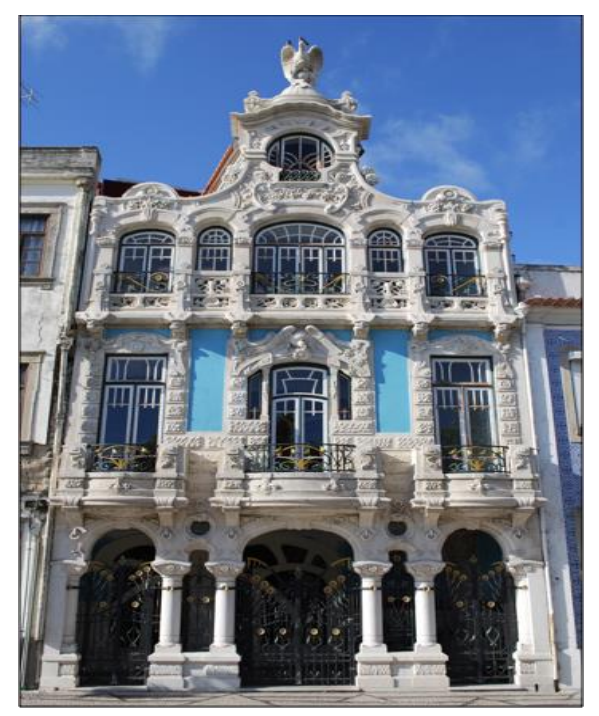

Figura 3 - Museu de Arte Nova, Aveiro, sediado na Casa do Major Pessoa, 1907-1909.

O conceito do Museu de Arte Nova assenta no pressuposto de que a coleção a apresentar é composta pelas mais de duas dezenas de casas Arte Nova que existem dispersas pelas ruas do centro de Aveiro, numa rota cujo ponto de partida é o Museu. A sede não contém espólio Arte Nova para além do próprio edifício, visando a exposição 
Carlos, Filipe Serra (2020). Desafios da divulgação do património Arte Nova em Portugal In Alice Duarte (ed.), Seminários DEP/FLUP vol. 1. Porto: Universidade do Porto, Faculdade de Letras/DCTP, p. 168-191. https://doi.org/10.21747/9789898969682/seminariosv1a8

permanente fazer, antes de mais, uma contextualização da época em que se desenvolveu esta estética. Para além disso, existe um espaço destinado a exposições temporárias de temáticas relacionadas com o tema do museu.

Para cumprir o objetivo de aproximar o património Arte Nova de um público mais alargado, o Museu possui um serviço educativo para desenvolver materiais didáticos e workshops junto das escolas do concelho e tem dinamizado iniciativas diversas, como por exemplo, a comemoração do Dia Mundial da Arte Nova (10 de junho).

\subsection{O Réseau Art Nouveau Network}

Prosseguindo o objetivo de estabelecer parcerias com outras cidades ligadas ao património Arte Nova, em 2008, Aveiro integrou o Réseau Art Nouveau Network. Esta Rede é uma associação internacional criada, em 1999, por iniciativa da cidade de Bruxelas, na Bélgica, que reúne cidades com importante espólio Arte Nova. Conta atualmente com 19 membros $^{7}$. O objetivo da Rede é promover a defesa e o conhecimento do património Arte Nova, para o que tem desenvolvido ao longo da sua existência projetos plurianuais que visam o reforço das relações entre os membros ao nível da partilha de experiências e conhecimentos para benefício de todos os associados (Horth, 2007: p. 73).

Assim, desde a sua integração no Réseau, Aveiro beneficiou da visibilidade internacional que obteve e, em particular, das oportunidades de integrar projetos internacionais em prol da salvaguarda e divulgação da Arte Nova local. Ainda antes de integrar o Réseau Art Nouveau Network, o município de Aveiro tinha já impulsionado o estabelecimento de parcerias nacionais, que viriam a resultar na criação, em 2006, da Rede Nacional de Municípios Arte Nova.

\subsection{A Rede Nacional de Municípios Arte Nova}

A iniciativa da Câmara Municipal de Aveiro de estabelecer contactos e parcerias com outros concelhos portugueses ao nível da promoção e salvaguarda do património Arte Nova resultou, em 2006, na fundação da Rede Nacional de Municípios Arte Nova. Conforme noticiava o Diário de Notícias, em 18 de junho de 2006, esta Rede contou com

\footnotetext{
${ }^{7}$ https://artnouveau-net.eu
} 
Carlos, Filipe Serra (2020). Desafios da divulgação do património Arte Nova em Portugal In Alice Duarte (ed.), Seminários DEP/FLUP vol. 1. Porto: Universidade do Porto, Faculdade de Letras/DCTP, p. 168-191. https://doi.org/10.21747/9789898969682/seminariosv1a8

o envolvimento de doze municípios que, em comum, têm o facto de possuírem significativos vestígios de Arte Nova nos seus territórios: Aveiro, Estarreja, Ílhavo, Espinho, Loures, Cascais, Caldas da Rainha, Figueira da Foz, Leiria, Lisboa, Porto e Vila Nova de Gaia ${ }^{8}$.

A Rede funciona sob a direção de uma equipa de coordenação bianual, sendo que a primeira era constituída pelos municípios de Aveiro e Estarreja, noticiava a Câmara Municipal de Estarreja em julho de $2006^{9}$. A cada equipa de coordenação compete definir o plano de ações a desenvolver nos seus dois anos de vigência. Numa comunicação, em 2006, Rosa Maria Rodrigues descreveu a criação desta Rede e enunciou, entre outros, os seus objetivos de conciliar políticas de intervenção e gestão do património Arte Nova, otimizar recursos no que respeita a candidaturas a incentivos para reabilitação, contribuir para a divulgação do património Arte Nova e necessidade da sua salvaguarda e estimular o turismo (Rodrigues, 2007: p. 89-90). Na sua notícia, o DN explicava ainda que, para a prossecução destes objetivos, logo aquando da sua criação, a Rede definiu como passos essenciais a levar a cabo pelos vários municípios a realização do inventário do património Arte Nova existente e a criação de roteiros com informação facilmente acessível, assim como visitas, workshops e outras atividades de enriquecimento cultural dos locais através da Arte Nova ${ }^{10}$.

De início, estipulou-se que todos os membros da Rede deveriam ter o inventário do respetivo património Arte Nova realizado durante o ano de 2006. Contudo, a informação disponível online não permite averiguar sobre a boa concretização deste objetivo. No primeiro biénio, previu-se também a atribuição de verbas para a criação de um site da Rede, que, ou nunca foi construído, ou já não está acessível.

\subsection{Iniciativas conjuntas da Rede Nacional de Município Arte Nova}

Embora a informação disponível online seja escassa, desde logo pela inexistência de um site oficial que concentre os registos relativos às atividades da Rede Nacional de

\footnotetext{
${ }^{8}$ https://www.dn.pt/arquivo/2006/doze-municipios-unidos-na-rota-da-arte-nova-642178.html, consultado em 03-10-2019.

${ }^{9}$ https://www.cm-estarreja.pt/noticias/2024, consultado em 03-10-2019.

${ }^{10} \mathrm{https}$ ://www.dn.pt/arquivo/2006/doze-municipios-unidos-na-rota-da-arte-nova-642178.html, consultado em 03-10-2019.
} 
Carlos, Filipe Serra (2020). Desafios da divulgação do património Arte Nova em Portugal In Alice Duarte (ed.), Seminários DEP/FLUP vol. 1. Porto: Universidade do Porto, Faculdade de Letras/DCTP, p. 168-191. https://doi.org/10.21747/9789898969682/seminariosv1a8

Municípios Arte Nova, os sites oficiais dos municípios e a comunicação social fazem-nos chegar ecos das iniciativas realizadas.

No âmbito de iniciativas conjuntas, reporta uma notícia da Universidade de Aveiro $^{11}$, conta-se a I Exposição da Rede Nacional de Municípios Arte Nova. Tratou-se de uma exposição itinerante que teve lugar, primeiro, em Aveiro, inaugurada em maio de 2008, donde seguiu para a Figueira da Foz e, de seguida, para os restantes municípios que tomaram parte na ação. Consistia num conjunto de 18 painéis informativos acompanhados de fotos de sete das cidades da Rede (Caldas da Rainha, Figueira da Foz, Estarreja, Ílhavo, Leiria, Loures e Porto).

A pesquisa específica sobre a relação entre a Rede e os municípios membros revelou pouca informação. Não surgem registos relativos às equipas de coordenação que se seguiram à inicial, nem notícias de ações conjuntas dinamizadas pela Rede e envolvendo os vários municípios. Assim, as ações parecem ter-se concentrado essencialmente nos primeiros anos de existência da Rede e terem partido mais da iniciativa do concelho de Aveiro. A falta de notícias relativas aos últimos anos deixa no ar a dúvida quanto ao estatuto da Rede - encontrar-se-á ainda ativa? - ou quanto ao cariz das atividades que são desenvolvidas - serão mais desenvolvidas por cada município autonomamente?

\subsection{Iniciativas dos membros da Rede Nacional de Municípios Arte Nova}

A pesquisa de informação relativa aos diversos municípios da Rede no que respeita à Arte Nova revelou-nos sinais de que cada um deles dispensou alguma importância à valorização do seu património Arte Nova nos últimos anos, quanto mais não seja ao nível da disponibilização de informação nos sites das Câmaras Municipais ou sites oficiais do turismo local. Contudo, a informação disponível é desigual e muitas vezes bastante superficial. As grandes exceções são o concelho de Aveiro, que, como vimos, fez uma aposta na Arte Nova sem comparação, e o concelho de Leiria, decorrente da importância que o arquiteto Ernesto Korrodi aí teve.

Em Aveiro, as ações relacionadas com a promoção do património Arte Nova têm estado principalmente na alçada do Museu de Arte Nova, destacando-se a criação da

\footnotetext{
${ }^{11}$ https://www.ua.pt/pt/noticias/0/22993, consultado em 04-10-2019.
} 
Carlos, Filipe Serra (2020). Desafios da divulgação do património Arte Nova em Portugal In Alice Duarte (ed.), Seminários DEP/FLUP vol. 1. Porto: Universidade do Porto, Faculdade de Letras/DCTP, p. 168-191. https://doi.org/10.21747/9789898969682/seminariosv1a8

personagem do Cavalheiro Arquiteto, uma personagem ligada ao imaginário da Arte Nova em Aveiro para integrar a produção de materiais didáticos e a realização de diversas exposições temporárias, para além de vários materiais impressos (Gomes e Lourenço, 2006). Merece referência também a organização, pela Câmara Municipal de Aveiro, já em 2006, do I Encontro Internacional de Arte Nova - Arte Nova, Porta para o Futuro.

Em Leiria, a Junta de Freguesia instituiu, em 2003, o Prémio de Arquitetura Korrodi, um prémio bienal que, no dizer da Ordem dos Arquitetos, citada numa notícia de 2008, visa "incentivar a qualidade arquitetónica de novas edificações e a recuperação ou remodelação de imóveis que contribuam para a salvaguarda do património edificado de Leiria" ${ }^{12}$. Embora a atribuição do nome seja uma homenagem a Ernesto Korrodi e ao seu filho Camilo, o prémio acaba, ainda que de forma marginal, por ser também uma celebração da Arte Nova, pela importância que esta estética teve na obra daquele arquiteto. Segundo o Jornal de Leiria, em 2019, a autarquia preparava-se para abrir um centro de interpretação sobre Korrodi (abertura que foi, entretanto, adiada para 2020) que funcionará como ponto central da Rota de Arquitetura Korrodi ${ }^{13}$. Não sendo uma Rota especificamente sobre a Arte Nova, coloca-a em destaque ao apresentar a vida e a obra deste artista, que foi um dos nomes maiores desta estética em Portugal, através das diversas atividades que são desenvolvidas (desde percursos pedestres a palestras, exposições e conceção de materiais didáticos). A Rota de Arquitetura Korrodi nasceu em 2005, na sequência de uma iniciativa particular em parceria com a Junta de Freguesia local antes de se tornar num projeto autónomo em parceria com várias outras instituições, como a Câmara Municipal de Leiria (Oliveira, 2006).

Em Ílhavo, encontra-se disponível informação online, no site da Câmara Municipal, sobre os exemplares Arte Nova mais dignos de destaque no concelho, informação que é complementada com dois roteiros de Arte Nova. As informações sobre o concelho não são muito exaustivas e as referências aos imóveis são bastante superficiais $^{14}$.

\footnotetext{
${ }^{12}$ https://www.construir.pt/2008/07/01/leiria-distingue-qualidade-arquitectnica-com-prmio-korrodi/, consultado em 07-10-2019.

${ }^{13}$ https://www.jornaldeleiria.pt/noticia/leiria-banco-de-portugal-abre-centro-de-interpretacao-korrod9829, consultado em 07-10-2019.

${ }^{14} \mathrm{https}: / /$ www.cm-ilhavo.pt/p/razoesparagostardeilhavo, consultado em 07-10-2019.
} 
Carlos, Filipe Serra (2020). Desafios da divulgação do património Arte Nova em Portugal In Alice Duarte (ed.), Seminários DEP/FLUP vol. 1. Porto: Universidade do Porto, Faculdade de Letras/DCTP, p. 168-191. https://doi.org/10.21747/9789898969682/seminariosv1a8

Em Estarreja, o site da Câmara Municipal apresenta uma página dedicada à Arte Nova no concelho, contextualizando de forma genérica o que é a Arte Nova e como se desenvolveu em Estarreja e apresentando informações sucintas sobre três dos espaços mais representativos ${ }^{15}$.

No concelho de Vila Nova de Gaia, a informação sobre o património Arte Nova reduz-se à apresentação daquele a que chamam o melhor exemplo de Arte Nova do concelho, mas que é remetido para a secção de "outros pontos de interesse" do site municipal ${ }^{16}$.

Nas Caldas da Rainha, além de uma proposta, disponível online, de roteiro de Arte Nova que passa por doze sítios do centro da cidade, em especial, são destacados os revestimentos em azulejo.

Na Figueira da Foz, sobressai a organização, a propósito das Jornadas Europeias do Património de 2016, de passeios turísticos e culturais incluindo "apontamentos sobre Arte Nova"17; e, a propósito das comemorações do Ano Europeu do Património Cultural, em 2018, de uma série de percursos temáticos pelo património, em que se integrou um dedicado à Arte Nova ${ }^{18}$. Para além disso, no site camarário, existe informação sobre património com referências à Arte Nova existente no concelho.

No Porto, o site oficial do Turismo do Porto tem uma página, datada de 2013, dedicada à Arte Nova na cidade, onde, para além de dar como exemplos as duas casas do Bairro das Carmelitas, se afirma haver pouca Arte Nova no Porto ${ }^{19}$.

\subsection{Para lá de Aveiro}

A divulgação da Arte Nova junto do grande público não está, no entanto, limitada às iniciativas de Aveiro e seus parceiros da Rede Nacional de Municípios Arte Nova. Devese a variadas entidades, públicas e privadas, a realização de atividades que levam o

\footnotetext{
15 https://www.cm-estarreja.pt/arte nova, consultado em 07-10-2019.

${ }_{16} \mathrm{http}$ ://www.cm-gaia.pt/pt/turismo/vivenciar/ver-visitar/outros-locais-de-interesse/, consultado em 07-10-2019.

${ }^{17}$ https://www.cm-figfoz.pt/index.php/noticias-lista/1942-jornadas-europeias-do-patrimonio-e-diamundial-do-turismo, consultado em 07-10-2019.

${ }^{18}$ https://www.cm-figfoz.pt/index.php/component/content/article/410-servicos2/portemas/cultura/projetos-iniciativas/projetos-iniciativas/2418-ano-europeu-do-patrimonio-cultural-2018, consultado em 07-10-2019.

${ }^{19}$ https://visitporto.travel/MaisPorto/Paginas/Cidade/artigo.aspx?artigo=145, consultado em 07-10- 
Carlos, Filipe Serra (2020). Desafios da divulgação do património Arte Nova em Portugal In Alice Duarte (ed.), Seminários DEP/FLUP vol. 1. Porto: Universidade do Porto, Faculdade de Letras/DCTP, p. 168-191. https://doi.org/10.21747/9789898969682/seminariosv1a8

conhecimento que se vai construindo sobre a Arte Nova até junto do público, mais conhecedor ou mais leigo, tanto em locais onde a Arte Nova é muito falada como naqueles onde é praticamente desconhecida. A título de exemplo, esteve patente na Covilhã, nos últimos meses de 2014, uma exposição de azulejos Arte Nova da coleção do Eng. Feliciano David. Esta exposição itinerante, que iniciou o seu périplo em Aveiro, em 2011 e percorreu várias cidades portuguesas, como a Figueira da Foz, Viana do Castelo ou Loures, deu bastante visibilidade à estética da Arte Nova na azulejaria.

Na sua etapa na Covilhã, a produção do catálogo motivou também a edição da publicação Itinerários: A Arte Nova na Covilhã, uma obra que apresenta uma contextualização histórica da Covilhã e da Arte Nova e, em especial, descreve uma rota composta de 13 imóveis, apresentando para cada um dos imóveis uma ficha com dados técnicos e informações detalhadas (Figura 4). Como que confirmando a necessidade de maior estudo e conhecimento sobre a Arte Nova, também nesta publicação se verifica a atribuição errónea a esta estética de um edifício oitocentista, o que, sendo naturalmente de lamentar, não belisca o meritório esforço realizado em prol da divulgação do património Arte Nova nesta cidade. No seguimento desta publicação, uma versão simplificada deste guia encontra-se hoje disponível, em PDF, no site da Câmara Municipal da Covilhã, constituindo o roteiro de uma de várias rotas temáticas que o visitante desta cidade pode explorar ${ }^{20}$.

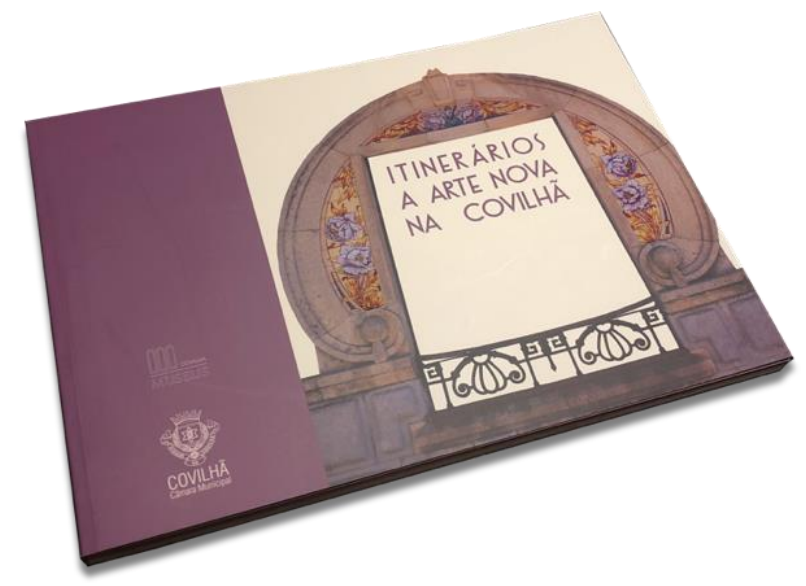

Figura 4 - Edição de Itinerários: A Arte Nova na Covilhã.

${ }^{20}$ http://www.cm-covilha.pt/?cix=899\&tab=793\&curr=862\&lang=1, consultado em 08-10-2019. 
Carlos, Filipe Serra (2020). Desafios da divulgação do património Arte Nova em Portugal In Alice Duarte (ed.), Seminários DEP/FLUP vol. 1. Porto: Universidade do Porto, Faculdade de Letras/DCTP, p. 168-191. https://doi.org/10.21747/9789898969682/seminariosv1a8

Ao nível da exploração turística do potencial da Arte Nova, o fácil acesso a roteiros é fundamental e deve-se a entidades oficiais, como as Câmaras Municipais, como já vimos, ou às Regiões de Turismo. A este nível, atualmente, destaca-se o Turismo do Centro de Portugal, que disponibiliza online muita informação relativa ao património Arte Nova existente na Região Centro ${ }^{21}$, como por exemplo a brochura Ria de Aveiro Roteiro de Arquitetura.

As sugestões de percursos para apreciar os vestígios da Arte Nova nas cidades portuguesas são também relativamente comuns em sites de divulgação de jornais ou outros portais de Internet, como o Sapo ou o Centro Nacional de Cultura em parceria com o Diário Económico 22 .

Ainda a propósito da Covilhã, a publicação do Itinerários propiciou também a realização de uma visita guiada a pé por parte de técnicos da Câmara Municipal, uma iniciativa cujo desejo de repetição foi manifesto. Evidencia-se, assim, a relevância dos passeios pedestres na divulgação do conhecimento da Arte Nova. Esta tem sido objeto tanto de visitas sobre essa temática específica, como no caso da Covilhã, referida dentro de percursos de temática mais genérica, como vimos acontecer na Figueira da Foz. Em Ílhavo, numa série de visitas intitulada Olhar por Dentro - Os Percursos da Arquitetura em Ílhavo, a Arte Nova foi a protagonista exclusiva de uma das sessões, ombreando com várias outras facetas fundamentais do território deste concelho. Esta série de visitas estava integrada na programação do 23 Milhas em 2017-2018, da Casa da Cultura de Ílhavo, e foi da responsabilidade de uma empresa de turismo cultural do Porto, a TalkieWalkie (Figura 5).

Vemos, assim, que este tipo de atividade acontece grandemente por iniciativa municipal, embora também com a colaboração de empresas privadas. Para além disso, deve realçar-se o contributo que as empresas de walking tours, crescentemente presentes nas cidades portuguesas mais turísticas, dão à divulgação do património Arte Nova junto do público. Tal é o caso de Aveiro, mas também de Coimbra, Setúbal ou Porto sobre as quais aparecem referências a empresas que, reconhecendo a atração que a Arte

\footnotetext{
${ }^{21} \mathrm{http}: / /$ www.cm-covilha.pt/?cix=899\&tab=793\&curr=862\&lang=1, consultado em 10-10-2019.

22 Por exemplo, https://www.e-cultura.sapo.pt//artigo/19361, https://www.cnc.pt/a-arte-nova-noporto/, consultados em 10-10-2019.
} 
Carlos, Filipe Serra (2020). Desafios da divulgação do património Arte Nova em Portugal In Alice Duarte (ed.), Seminários DEP/FLUP vol. 1. Porto: Universidade do Porto, Faculdade de Letras/DCTP, p. 168-191. https://doi.org/10.21747/9789898969682/seminariosv1a8

Nova exerce sobre os sentidos, realizam passeios pedestres que de forma mais ou menos centrada neste fenómeno dão relevo à Arte Nova ${ }^{23}$.

O interesse pela Arte Nova em Portugal manifesta-se também num site estrangeiro - o Art Nouveau Club ${ }^{24}$ - dedicado a ajudar os amantes da Arte Nova a descobri-la em várias cidades europeias, propondo para isso aos seus clientes diversos tours privados em cada cidade. Desde 2017, inclui quatro propostas para Portugal, centradas no Porto e em Aveiro (Fig. 6).

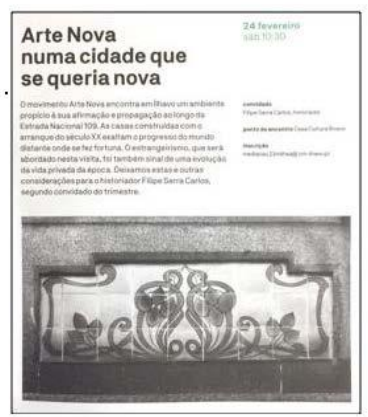

Figura 5 -Divulgação de uma visita sobre Arte Nova, em ílhavo.

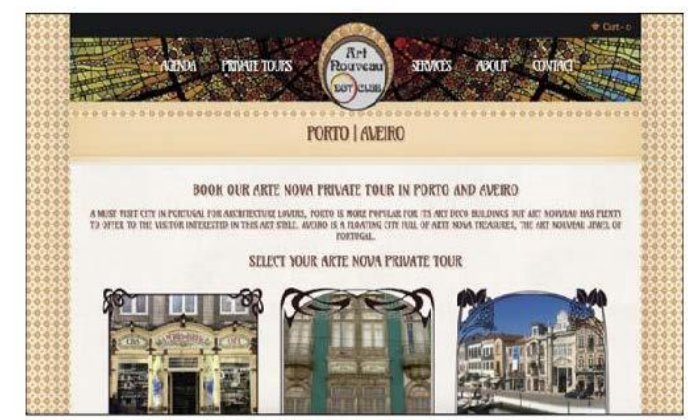

Figura 6-Tours em Portugal, propostos no site Art Nouveau Club

Por fim, cabe ainda referir o papel dos museus neste quadro. Para além do Museu de Arte Nova, de Aveiro, também a Casa-Museu Dr. Anastácio Gonçalves, em Lisboa, tem dedicado, de vez quando, nas atividades que desenvolve, alguma importância à Arte Nova, nomeadamente no âmbito dos serviços educativos e da organização de palestras, como o Colóquio A Arte Nova em Portugal, realizado em $2008^{25}$.

Segundo notícias em vários órgãos de comunicação social, como o Diário de Notícias, esteve em vias de ser constituído, em Lisboa, o Museu Berardo-Arte Nova, Art Déco para expor a coleção de pinturas, mobiliário, esculturas, cerâmicas e cristais e objetos decorativos do colecionar de arte Joe Berardo. Previsto para 2017 e com abertura adiada sucessivas vezes, se viesse a concretizar-se, este Museu seria mais uma

\footnotetext{
${ }^{23}$ A título de exemplo, veja-se a proposta da empresa de animação turística setubalense SAL - Sistema de Ar Livre: http://www.sal.pt/m1_agenda_passeios/pp_setubal da_elegante arte nova.shtml, consultado em 11-10-2019.

${ }^{24}$ https://artnouveau.club, consultado em 12-10-2019.

25 http://blogdacmag.blogspot.com, consultado em 12-10-2019.
} 
Carlos, Filipe Serra (2020). Desafios da divulgação do património Arte Nova em Portugal In Alice Duarte (ed.), Seminários DEP/FLUP vol. 1. Porto: Universidade do Porto, Faculdade de Letras/DCTP, p. 168-191. https://doi.org/10.21747/9789898969682/seminariosv1a8

oportunidade de atrair a atenção do público para as várias dimensões deste fenómeno $\operatorname{artístico~}^{26}$.

\section{Conclusões}

Os estudos sobre a Arte Nova em Portugal iniciaram-se nos anos 50 do século XX e foram fundamentais para dar visibilidade a uma expressão da arte portuguesa que, depois de ter passado de moda, ficou esquecida. Esses estudos estabeleceram a visão da Arte Nova que perdurou durante as décadas seguintes, não a valorizando particularmente, em especial quando comparada com outras expressões da arte portuguesa ou com a Arte Nova dos grandes centros europeus tomados como referência.

$\mathrm{Na}$ sequência do enfoque dado à Arte Nova pelos estudos académicos, verificaram-se as primeiras classificações de património Arte Nova, nos anos1970. A evolução do número de imóveis classificados com características atribuíveis a esta estética revela, na última década, uma fase de interesse crescente que beneficia, por um lado, do investimento que tem vindo a ser feito na exploração do potencial económico da Arte Nova, em particular tendo em vista fins turísticos, e, por outro, da sensibilização para a necessidade de preservação deste património. No fundo, são duas vertentes dependentes entre si.

A cidade de Aveiro tem desempenhado um papel fundamental, tendo desenvolvido uma estratégia que passou pela criação de um Museu e pelo estabelecimento de parcerias com diversas cidades Arte Nova, tanto nacional como internacionalmente. Para dar a conhecer a Arte Nova e divulgar o património existente, a criação e disponibilização de roteiros revela-se a ferramenta mais comum e eficaz, que é frequentemente complementada com a realização de passeios guiados, atividade que tem proporcionado a participação de agentes privados. Isto pressupõe, contudo, a existência de informação rigorosa e completa que apenas a promoção de estudos pode

\footnotetext{
${ }^{26}$ https://www.dn.pt/lusa/atrasos-nas-obras-do-museu-art-deco-adiam-abertura-para-julho-deste-ano10465345.html, consultado em 12-10-2019.
} 
Carlos, Filipe Serra (2020). Desafios da divulgação do património Arte Nova em Portugal In Alice Duarte (ed.), Seminários DEP/FLUP vol. 1. Porto: Universidade do Porto, Faculdade de Letras/DCTP, p. 168-191. https://doi.org/10.21747/9789898969682/seminariosv1a8

assegurar, no sentido, por um lado, de conhecer mais a fundo as especificidades e a dimensão da Arte Nova no nosso território e, por outro, de desfazer mitos e equívocos que ainda perduram - não apenas no público mais leigo -, como por exemplo a dificuldade em a distinguir, o que a leva a ser confundida com a Art Déco ou com outros estilos arquitetónicos que a antecederam.

Do cenário aqui esboçado em linhas gerais, sobressai a impressão de que a Arte Nova em Portugal vive um período de popularidade. Sem dúvida, encontra-se já muito distante da realidade de há mais de meio século, quando se publicaram os primeiros estudos sobre ela, mas está a percorrer um caminho ainda longe de estar terminado.

\section{Referências bibliográficas}

Almeida, Artur Jorge (2007). Turismo e Arte Nova. In Arte Nova, Porta para o Futuro: Livro das comunicações do I Encontro Internacional de Arte Nova (2007). Aveiro: Câmara Municipal de Aveiro.

Almeida, Pedro Vieira de, \& Fernandes, José Manuel (1986). A Arquitectura Moderna. In História da Arte em Portugal, vol. 14. Lisboa: Publicações Alfa.

Câmara Municipal de Aveiro (2007). Arte Nova, Porta para o Futuro: Livro das comunicações do I Encontro Internacional de Arte Nova. Aveiro: Câmara Municipal de Aveiro.

Câmara Municipal da Covilhã (2014). Itinerários: A Arte Nova na Covilhã. Covilhã: Câmara Municipal da Covilhã.

Fernandes, José Manuel (1993). A Arquitetura Modernista em Portugal. Lisboa: Gradiva.

França, José-Augusto (1966). A Arte em Portugal no Século XIX, vol. 2. Lisboa: Bertrand.

Gomes, Ana, \& Lourenço, Andreia (2007). Museu Arte Nova: Estratégia Integrada de Desenvolvimento Museológico. In Arte Nova, Porta para o Futuro: Livro das comunicações do I Encontro Internacional de Arte Nova. Aveiro: Câmara Municipal de Aveiro.

Horth, Elisabeth (2007). Réseau Art Nouveau Network: Art Nouveau \& Société 20052008. In Arte Nova, Porta para o Futuro: Livro das comunicações do I Encontro Internacional de Arte Nova. Aveiro: Câmara Municipal de Aveiro. 
Carlos, Filipe Serra (2020). Desafios da divulgação do património Arte Nova em Portugal In Alice Duarte (ed.), Seminários DEP/FLUP vol. 1. Porto: Universidade do Porto, Faculdade de Letras/DCTP, p. 168-191. https://doi.org/10.21747/9789898969682/seminariosv1a8

Oliveira, Genoveva (s.d.). Ernesto Korrodi: Roteiro na Cidade de Leiria. Leiria: ADLEI Associação para o Desenvolvimento de Leiria; CEPAE - Centro do Património da Estremadura; Delegação Distrital de Leiria da Ordem dos Arquitectos.

Oliveira, Genoveva (2007). Um Projeto de Defesa do Património, Rota de Arquitetura Korrodi, na Cidade de Leiria. In Arte Nova, Porta para o Futuro: Livro das comunicações do I Encontro Internacional de Arte Nova. Aveiro: Câmara Municipal de Aveiro.

Pereira, Paulo (org.) (1995). História da Arte Portuguesa, vol. III. Lisboa: Círculo de Leitores.

Providência, Francisco, \& Providência, Paulo (2007). Arte Nova, Porta para o Futuro: Livro das comunicações do I Encontro Internacional de Arte Nova. Aveiro: Câmara Municipal de Aveiro.

Portas, Nuno (1973). A Evolução da Arquitetura Moderna em Portugal: uma interpretação. In Bruno Zevi, História da Arquitectura Moderna, vol. 2. Lisboa: Editora Arcádia.

Rio-Carvalho, Manuel (1957). "Modern Style", "Art Nouveau" e "Arte Nova": Respectivas situações. Arquitectura, n. 60.

Rio-Carvalho, Manuel (1966). Para uma compreensão da Arte Nova. In Colóquio/Revista de Artes e Letras, n. 41.

Rio-Carvalho, Manuel (1974). A "Arte Nova": Modernidade Domesticada, Sentimentalidade Projetada. In Estética do Romantismo em Portugal: Primeiro Colóquio 1970. Lisboa: Centro de Estudos do Século XIX do Grémio Literário.

Rio-Carvalho, Manuel (1975). Em 90\% dos casos a Arte Nova em Portugal foi uma gramática decorativa. Binário, n. 201.

Rio-Carvalho, Manuel (1986). Do Romantismo ao fim do século. In História da Arte em Portugal, vol. 11. Lisboa: Publicações Alfa.

Rodrigues, Rosa Maria (2007). Rede Nacional de Municípios Arte Nova. In Arte Nova, Porta para o Futuro: Livro das comunicações do I Encontro Internacional de Arte Nova. Aveiro: Câmara Municipal de Aveiro.

Turismo Centro de Portugal [brochura] (s.d.). Ria de Aveiro - Rota da Arquitetura. s.l.: Turismo Centro de Portugal. 